\title{
Family Resourcing for Sustainable Living
}

\author{
Aparajita Chowdhury \\ Department of Home Science, Berhampur University, Berhampur, Orissa, India \\ E-mail: jitabpur@sancharnet.in / aparajitabpur@yahoo.co.in
}

KEYWORDS Resourcing; sustainable; strengthening; partnership

\begin{abstract}
It is becoming increasingly apparent that the future of any society depends on the ability of its citizens to develop their full potential and have the opportunity to lead productive and meaningful lives. The family no doubt plays a critical role in this endeavor. However, contemporary Indian families are encountering complex and disturbing problems of varied nature both internal and external having far reaching consequences. Families of today faces crises such as - marital strain and dissolution, increased parent-child conflicts, various forms of family violence, substance abuse, juvenile delinquency, school drop outs or low school attainment among the lower class, and excessive pressures in many middle class families for children and adolescents to achieve academically. Given these conditions and difficulties, the future well-being of the Indian family seems to be uncertain. Family resourcing thus would benefit from having resources available at times of increased stress and strains. Assistance in resourcing can allow families facing crises or stresses to take advantage of their family and social network, as well as free or low cost social services. It encourages in identifying family strengths, building collaboration within and outside the family and highlights the interdependence of systems. Present paper discusses about the various elements and areas of family resourcing for sustainable living in contemporary Indian society. Most of the Indian families being resource-limited can well be helped through family resourcing to enable its members to lead healthy, happy and resilient family life.
\end{abstract}

"Sustainable development" is the development that not only generate economic growth but distributes its benefits equally, that regenerates the environment rather than destroying it, that empowers people rather than marginalizing them" (Srivastava, 2001). Sustainable development is that development that is pro-people, pro-nature, pro-employment, pro-women, pro-family and one that pave the way for future collective welfare. However, we are in $21^{\text {st }}$ Century, still the question is - are we sustaining development in the interest of global capitalism and a globalized patriarchy? This is thriving on consent rather than coercion and outright oppression or the so-called dominant mode of production. Therefore, when we talk of sustainable development, we need to focus the basic human nature and thinking (Srivastava, 2001).

Nature has been increasingly commodified. Thus, the gift of nature, which all human beings freely enjoyed, and which enabled them to lead a life of self-sufficiency from their surroundings became marketable and come under either the control of industrial capitalists, multinational companies (MNC's) who had authority, wealth or arms. We have to even challenge the patriarchal systems, which perpetuate exploitation and gender inequalities, starting from the family itself. The development paradigm borrowed from patriarchal and capitalist has contributed to the increase in grave disparities between the classes and sexes and has led to the criminal degradation of environment, which diminishes the means of survival of poorest among the poor of our society (Bhasin, 1997).

The alternative for sustainable development will have to be found in locally based, ecologically sustainable alternatives, such as from the root level, that is the family. It is the place where every human individual grows, develops and socialized to become a responsible member of the society. Without proper development of the "family", being the primary social unit, sustainable development cannot be possible. This being the only single most area where we can talk of holistic development in long run. If we want our society to develop, it is from the family the efforts need to be started.

\section{CHALLENGES FACED BY THE CONTEMPORARY INDIAN FAMILIES}

India is a rapidly developing country, which, in next 16 years or so is expected to be a developed nation on earth. As the world's largest democracy, secular and welfare state, it includes within its boarders ancient and diverse cultures, languages, and religions. Family has always been at the foundation of Indian society. Contemporary Indian people continue to take pride in the centrality of marriage and family life. Interdependency, support and nurturing across 
the generations are uniquely valued in the Indian family system. Despite unparallel modernization and globalization in recent decades, millions of India families, both rural and urban, have remained undeniably close and resilient.

However, contemporary Indian families are encountering complex and disturbing problems. Majority of Indians are still poor, illiterate, lack basic necessities of life such as safe drinking water, proper transportation and communication, health and education services for their general growth and welfare. At the same time they are also experiencing a multitude of difficulties, such as increased domestic violence, inadequate housing and sanitation; poor nutrition and health care; minimal enforcement of child labour and child abuse laws; etc which are equally challenging for the family functioning, putting the families "at-risk". In addition to it increased crime, social violence, and terrorism facilitates more than impedes the cycle of poverty.

Other changes are having far reaching implications for Indian family such as in social, cultural, economic and political life. These include the widespread growth of women's education and employment; impact of mass media; globalization and economic liberalization; and most importantly corruption in every sphere of our life. In the age of electronic media, specially television, computers and mobile phones even in remotest areas, the family is being exposed to ideas, ideals and values swept across distant societies. More recent crisis in families encompasses many of the same kinds of problems that have plagued the western society in last century. These include marital strain and dissolution, parent-child conflicts, various forms of family violence, substance abuse, juvenile delinquency, school dropouts or low school attainment in all sections of the society. Further, there are excessive pressures in many middle and upper class families for adolescents and young adults to achieve academically and get successful employment. Moreover, unlike past, elderly members of the family are not only have few roles to play in child socialization, but also are less likely to live with their adult children and grandchildren due to increased mobility and intergenerational gap. No more the aged in Indian families are accepted as "assets", rather are being considered as "liabilities" on their children. In addition, in many families there is absence of clear-cut and consistent role models for the children beyond their own parents. The electronic media aggravates the situation by creating unrealistic aspirations in children, adolescents as well as in parents, including - "I should have it" mind set.

Focus on Dual Earner Families: One of the most striking social trends of our country is the progressive influx of women in to the labour force, after marriage and childbirth. Families with employed women are rapidly becoming the norm of both rural and urban India. Women in India represent 48.3 percent of the total population (500 million). Out of which, the number of women in labour force is around 130 million (26\%) that is about one third of the total labour force of our country. Approximately, there are half of the all employed women in childbearing and child-rearing age, which emphasizes the need for proper understanding of these mothers, which will aid them to raise their families efficiently.

"A woman's work is never done", so goes the old saying about women's responsibilities towards their families, especially with children and adolescents at home. If one adds to home care and motherhood, full time employment in the labour force, mother's job requires 50\% more hours than of the employed fathers and single women without children. Women all over the world work longer hours than men (Tavris and Wade, 1984). An employed woman in India with young children or adolescent faces very many problems both at home and work place. When we are discussing about sustainable development of our society, how can we ignore this major issue, as the problems arising out of women's dual role depends on social, economic, and political environment of our present day society?

Despite very many problems, present day women continue working outside the home to support their families, and contribute greatly for the development and welfare of our country. "Work and family" and "work and children" has already occupied its positions in women's lives. Thus, understanding, supporting and developing viable options for the general welfare of our families in India is essential. For working parents, the most pressing issues are shared family responsibilities, spousal support, the affordability and availability of consistent and dependable childcare. Thus, there needs to be legislation, enforcement and coordinated efforts between the private and government sectors to provide systematic, qualitative and comprehensive services for dual earner families. Employers need 
to be encouraged to take more responsibility for the necessary balance of family and work life of their employees, so as to increase their productivity (Chowdhury, 1995). At the same time, creating awareness and sensitizing the male members of our society towards the burden, difficulties and challenges faced by the women both at home and work place is necessary. This will help our educated, skilled and professionally trained female population to participate in the nation building activities on larger scale.

\section{FAMILY RESOURCING TO STRENGTHEN FAMILY LIFE}

Family resourcing encourages in identifying family strengths, builds collaboration and highlights the interdependence of systems. According to Karpel (1986) family resources are "those individual and systematic characteristic among family members that promote coping and survival, limit destructive patters, and enrich daily life". The need for family resourcing comes from the difficulties faced by the families in every stages of family life cycle. Study conducted by Carson, Chowdhury and Pati (1999) indicated that building family strengths would tend to enhance children's competence, especially in countries like India where immediate and extended family members play unique and powerful role in the lives of the next generation. Several exploratory studies also indicated that underutilization of family resources are the main reasons for creating stresses and strains than lack of it. An exploratory study on Scheduled caste and Scheduled tribe adolescents of Orissa state highlights the importance of particular family and community protective factors that promote successful development in adolescents reared in extremely resource-limited rural families in India (Carson, Chowdhury, Choudhury and Carson, 2002). Another study conducted by Patnaik (2003) on pre-school and elementary school children in Orissa state indicated that lack of parental awareness, knowledge and skills in child care were the main cause of children's mental health problems. The study viewed that family factors play significant role in maintaining and enhancing children's mental health. Further, this study showed that early identification of mental health condition among children and timely family based intervention would enhance children's mental health in our society.
Thus, family resourcing can play a significant role, not only creating better individuals, but also strong family and healthy society as well. In today's competitive world, all possible resources needs to be utilized to get the best benefits out of it. So, why not use the available family resources to the maximum for family well-being?

Elements of Family Resourcing: There are three major elements of family resourcing as proposed by Karpel (1986), which is essential for understanding and making use of it wherever possible and required for maximum benefits. They are:

- The ability to access coping and survival techniques. Families face a variety of predictable as well as unpredictable stressors throughout the family life cycle. Families vary widely in their resources for promoting coping and survival (Pell and Cohen, 1995). Some families cope well with the challenges, while others struggle. Those who struggle with coping daily may benefit from family resourcing. Family resourcing promote resiliency in all family members to face any kind of adversities and eventualities.

- Another element of family resources identified by Karpel is the ability of the family to limit destructive patterns. This relates both to external stressors and to internal patterns such as attacking, demeaning, neglecting, or diminishing another. Limiting destructive patterns helps to prevent stressors from piling up within family. Some families seem to resist destructive patterns like immunological resistance. An example of resistance is - parent's exercising a clear hierarchy over an out-of-control adolescent, and a child's resistance to being triangulated in to the parents' conflicts.

- A third element of family resource relates to the ability to enrich and enjoy daily life. This element goes beyond dealing with problems and centers on life's more rewarding aspects, such as - caring and sharing, satisfaction, and pleasure. The ability to bounce back is one of the characteristics of resiliency - is enhanced by the family's ability to enjoy simple aspects of daily life.

Thus, there are personal as well as rational resources available in any family. Personal resources include self-respect, protectiveness, hope, tolerance, and affection. Relational 
resources include respect, reciprocity, reliability, repair, flexibility, family pride, and loops of interaction. Both personal and relational resources within families are affected by three characteristics such as: capacity, rules, and active efforts. For example - the relational resource of reciprocity or give-and-take, in a family to relates to how the family balances and holds fair play. Thus, assessment of each family member's capacity for reciprocity and consider this in conjunction with family rule (e.g., father is the disciplinarian). Accordingly, active efforts by family members to initiate and collaborate on reciprocity can be considered.

Areas of Family Resourcing: Basically there are four areas of family resourcing which are helpful to understand and make efforts to strengthen the family life. The first area of family resourcing in Indian context has to do with religion, caste, class, culture and racial identity. Most of our family functioning, dynamics, upbringing, believe system of the family members are greatly shaped by particular religious believe, caste and class to which the family members belong to. Thus, while trying to get the maximum benefits from particular family's strength, better avoid comparing it with other families, especially from other backgrounds. Looking for family strengths in other's background is helpful and being aware of differences is critical to avoid misinterpret ting behaviour. Families usually identify with religious groups or faith, and this allegiance serves as a family resources. Temples, Gurudwaras, Church and Mosques have considerable resources that might be tapped positively in helping families. This linkage is important as family reach out to community resources and form partnerships for mentoring and other resiliency building programs. Unless and until the families are rich and healthy, no society can develop.

Second area of family resource relate to the family's inner-language or communication, which, identifies it as a family both to family members and to others. Communication is vital to a satisfying family life. According to Bochner (1976), "the most fundamental aspect of family process is communication". Hence, understanding of communicative process may be most important factor in achieving the kind of family we desire. Communication with our family members is affected by the nature of the family unit. The family context imposes unique constraints on our interactions. Communication allows us to demonstrate our understanding and support to other family members, to establish autonomy and intimacy, to resolve conflict, to manage power, stress and to make decisions. Clear, consistent and free communication between family members and with outside family is catalyst for better family functioning. In order to increase the family language and communication, myths, metaphors, jokes, humor, and words or phrases with special meaning to the family members can be use at appropriate times. When the family is going through a particularly rough time, family members can be encouraged to use language, which will be psychologically boosting, refreshing and soothing rather than depressing. For example, laughing at the face of sadness.

A third area of family resource relates to individual and family commitment, loyalties, or a sense of connections. Family values are important for making the family healthy, happy and stable. Unless and until the family members are committed to their family and have a sense of connectivity with each other, family life can not be stable and peaceful.

The fourth area relates to the capacity of the family to interact with the outside world in such a way that preserves and enhances its integrity and dignity as a family. Families have rules for dealing with the external world, beyond family, in the same way the rules develop for family relationships. For example - family's relationship with other systems of the society such as, school. If the relationship with school is warm, close and open, it will definitely have positive impact on children's learning and development. Moreover, collaborating with family, the school can also be able to achieve its goal of rendering best education.

It is however, essential to recognize these family resources, so that its utilization can be well planned to achieve the goal of healthy, wealthy and happy family. Further, enrichment of family resources can be done through connecting to other major systems such as - extended family and sibling sub-system. The potential strength of our Indian families lies in the extended families. Very often, family members may overlook the real possibilities the extended family has to offer. Extended family members can serve as important role models for coping with stress and for increasing resiliency in children and youth. Moreover, sibling sub-system can also be utilized as a source of support and a valuable family 
resource. In order to get the maximum from the existing family retreats, family playgroup, counseling, and parent education groups can be implemented.

Thus family resourcing is necessary for strengthening and enriching the family life. Family strengths are "made" and not "born". Proper use of family resources (both material and human) can enhance the strength of family to face the challenges of today. All families have the potential for "growing", by encouraging their best efforts and strengthening key processes. On the basis of these principles, families can better asses their crises situations and identify ways to reduce risk factors, rendering challenges less threatening and more manageable. Further, learning new skills, adapting positive attitudes, accepting situations as and when it occurs within family, make a difference in the lives of the individuals, families and communities. Thus, in order to strengthen family life for sustainable living certain practical considerations can be suggested, such as:

- Identifying available family resources.

Making use of family resources.

Adopting positive family oriented goals.

Inculcating family values and religious faith.

- Understanding family crisis situation and making sense of it.

- Parent education and family support.

- Applying humor in communication and family activities.

- Facilitating effective coping skills.

- Developing creativity among family members.

"Families thus can be empowered not by dwelling on what is wrong with them, but on that which is strong already and can be built upon".

\section{UNDERSTANDING PARTNERSHIP IN ENHANCING FAMILY LIFE}

Given the unique Indian situation of geographical vastness and socio-cultural diversity within and between the states and religions, it is imperative that the government machinery plays the dominant role in improving the condition of the millions of the people in our country. Government machinery includes the vast bureaucratic establishment, judiciary, people's institutions, and government promoted developmental agencies. Along with, nongovernmental organization (NGOs) is continuing to play a crucial role in the overall developmental efforts in the country. Within the government machinery, coordination among the different departments and interface between these departments and non-government organizations are important for eliciting benefits at the grass-roots level. In most of the cases, both government departments and NGOs work in isolation, having absolutely no connectivity among each other. Thus, the result is big projects are there for the general welfare and development of the people, with millions of money spent without achieving its target objectively. Unless and until intersectorial partnership in planning, implementing and evaluating is being done, total benefits may not be possible to achieve.

Intersectorial partnership is equally essential for sustainable family living. With all competitive, fast and ever changing nature pf our society, present day family needs to be updated, equipped and must get the feed back for its efficient functioning. There is the necessity for having partnership between academic research institutes/ organizations with that of Government policymaking body, voluntary/NGO's working for the welfare of the families for sustainable living. Family as a basic social unit may lag behind, and unable to keep pace with the changing nature of the society. With rising younger population in our country (about $54 \%$ below 25 years age), there is thus need for such type of interface to make them competent for future family life.

The main focus of intersectorial partnership in this paper is on the academic research on family life and utilization of its feedback in governmental and non-governmental sectors working for the overall development of the human resources. Since, the newly build globalized economy demands new dimensions of research to produce innovative knowledge and expertise through new facets of methodology. Family research needs to be reoriented accordingly to provide new knowledge, create productive information to achieve sustainable living according to the demands of the society in a continuous process. Further, the interaction between plan and process of implementation may have various models suitable for the country's necessity. Hence, with proper interactions between the researchers, professionals and government and non-government agencies, the plan can well be implemented and better outcome can be expected as well.

Those concerned with the very survival and development of families in our country face the difficult challenge of recovering the holistic and 
comprehensive view of development that has been eroded by technological specialization. Respecting the holistic nature of Indian families, collaboration between existing bureaucratic structures, each established for a specific purpose, is not an easy task. Further, academic and research institutes in this country must come forward for extension activities in the field level. The knowledge learnt would have to be translated in to action that is what we need to do for sustainable development of our society.

\section{CONCLUSION}

Family in India is a living, vibrant institution. It is in the process of reshaping its own image. In all probability it is likely to survive the onslaught of external and internal forces and challenges. It is possible, provided it is prepared and equipped accordingly with proper intervention to protect its values and ethos. The complexity of today's socio-cultural and economic milieu, the multiplicity of forces working upon the individual, the widening intergenerational gaps require an educational approach which is likely to assist the family members to asses his/her role to create a healthy and happy family life. Moreover, workingwomen and men are struggling daily to balance the demands of jobs and families. No longer does the typical family is providing the atmosphere and preparing the individual to face the challenges of outer world. Government and employers have not yet kept the pace with these changes to provide necessary support to its employees (both male and female) for better life and thus more productivity. The main issue of childcare, child support and the family related issues need to be dealt by the employers in our country. A "National Family Policy" needs to be developed to protect the families' interest and welfare, so that we can strengthen our families and individuals, by which we can ultimately strengthen our economy, our political system and our national security.

\section{REFERENCES}

Bhasin, K. 1997. "Participatory development demands participatory training." ICCW Journal, IV(3 \& 4):30-38.

Bochner, A.P. 1976. "Conceptual frontiers in the study of communication in Families: An introduction to the literature." Human Communication Research, 2: 381-397.

Carson, D.K., A. Chowdhury, R. Choudhury and C. Carson. 2002. "Competence and Family support of Vulnerable and Invulnerable Adolescents representing Schedule Castes and Scheduled Tribes in India." Journal of Comparative Family Studies, 33(2): 249 $-270$.

Carson, D.K., A. Chowdhury, C. Perry and C. Pati. 1999. "Family characteristics and adolescents competence in India: An investigation of Youth in South Orissa." Journal of Youth and Adolescence, 28(2): 211 233.

Carson, D.K. and A. Chowdhury. 2000. "Family therapy in India: A new profession in an Ancient Land?" Contemporary Family Therapy, 22(4): 387 - 406.

Chowdhury, A. 1995. "Employed mothers and their Families in India." Early Child Development and Care, 113: 65-75.

Garain, S. 1994. "Government-NGO interface in India: An overview." Journal of Social Work, LV(3): 337347.

Karpel, M. (Ed.). 1986. Family Resources: The Hidden Partner in Family Therapy. New York: Guilford.

Patnaik, I. 2003. Effects of Critical Socializing Effects on Mental Health of School Children. Unpublished Ph.D. Thesis in Home Science, Berhampur University, Orissa, India.

Pell, E.C. and E. P. Cohen. 1995. "Parents and advocacy systems: A family system approach.", in M.C. Wang, M.C. Reynolds and H.J. Walberg (eds.), Handbook of Special and Medical Education: Research and Practice. New York: Elsevier Science.

Srivastava, A. 2001. Feminist Re-definition of sustainable development. Social Welfare, December, pp. 8-14. 